\title{
Correction to: 20 Years of G20
}

\author{
Rajat Kathuria and Prateek Kukreja
}

\section{Correction to:}

R. Kathuria and P. Kukreja (eds.), 20 Years of G20, https://doi.org/10.1007/978-981-13-8106-5

The original version of the book was inadvertently published without abstracts for the chapters 3, 6, 8, 9 and 11. The missing abstracts have now been included. The book has been updated with the changes.

The updated version of these chapters can be found at https://doi.org/10.1007/978-981-13-8106-5_3

https://doi.org/10.1007/978-981-13-8106-5_6 https://doi.org/10.1007/978-981-13-8106-5_8 https://doi.org/10.1007/978-981-13-8106-5_9 https://doi.org/10.1007/978-981-13-8106-5_11

https://doi.org/10.1007/978-981-13-8106-5

(C) Indian Council for Research on International Economic Relations (ICRIER) 2019 